\title{
Does Distance Matter? Exploring the links among Values, Motivations, Home location, and Satisfaction in Walking Trips
}

\author{
Kevin Manaugh \\ PhD Candidate \\ School of Urban Planning \\ McGill University \\ Suite 400, 815 Sherbrooke St. W. \\ Montréal, Québec, H3A 2K6 \\ Canada \\ Tel.: 514-398-4075 \\ Fax: 514-398-8376 \\ E-mail: kevin.manaugh@mail.mcgill.ca
}

\author{
Ahmed M. El-Geneidy (Corresponding Author) \\ Assistant Professor \\ School of Urban Planning \\ McGill University \\ Suite 400, 815 Sherbrooke St. W. \\ Montréal, Québec, H3A 2K6 \\ Canada \\ Tel.: 514-398-8741 \\ Fax: 514-398-8376 \\ E-mail: ahmed.elgeneidy@mcgill.ca
}

\section{Link to Publisher version: \\ http://www.sciencedirect.com/science/article/pii/S0965856413000670}

For citation please use : Manaugh, K., \& El-Geneidy, A. (2013). Does Distance Matter? Exploring the links among values, motivations and satisfaction in walking trips. Transportation Research Part A: Policy and Practice, 50, 198-208. 


\title{
Does Distance Matter? Exploring the links among Values, Motivations, Home location, and Satisfaction in Walking Trips
}

\begin{abstract}
This research utilizes a large-scale travel survey that captures two important-but often overlooked-elements: traveler motivations and satisfaction levels. Attitudes towards exercise, social interaction, and the environment are central motivations affecting individual's choice of mode. Trip satisfaction is a complex element that has important ramifications for understanding travel behavior. Using clustering techniques, walkers are stratified into one of six distinct groups based on underlying values and motivations. Among other findings, people who are most concerned with environmental issues and physical activity are walking much longer distances than average and are much more satisfied with their commute. In addition, a new conceptual model of walking behavior is presented that suggests that underlying values lead to home location decisions while simultaneously having a moderating effect on the perception and satisfaction with travel. This research adds to the burgeoning debate surrounding how various aspects of travel can best be measured, conceptualized and modeled for better public policy.
\end{abstract}

Key words: Walking, travel behavior, satisfaction, active transportation, residential selfselection 


\section{INTRODUCTION}

As active transportation has well-documented health, environmental, economic, and social benefits researchers and policy-makers in the domains of urban transport planning, public health and other fields have begun exploring how to increase utilitarian walking and identifying individual or built-environment characteristics associated with these desired behaviors. However, these studies or research frameworks do not fully account for the personal motivations or preferences of travellers which may vary dramatically in terms of environmental awareness or attitudes towards physical activity and exercise. Failure to account for these and other oftignored factors may result in the attribution of a disproportionate significance to the physical environment as a predictor of the decisions to use active transportation (Alfonzo, 2005; Cao, Mokhtarian, \& Handy, 2009). Recent finding suggest that individuals of various socio-economic groups respond differently to the same built environment factors often assumed to uniformly promote walking trips (Manaugh \& El-Geneidy, 2011).

In addition, the degree of trip satisfaction experienced by active mode users is an underexplored element in much transport research. This may be due to the growing preoccupation with active transportation as a solution to the problems of obesity and climate change. While GHG emissions reductions are commonly translated into economic terms (Hoffman, 2005). Issues of personal satisfaction with trips derived from transportation decisions and other quality-of-life issues are typically more difficult to quantify.

Central to this research is the recognition that individuals walk for a host of different reasons, including, but not limited to exercise, concern for the environment, convenience or simply out of necessity (because other options are either not affordable or available). It is hypothesized that people with a professed motivation to engage in exercise or environmentally 
benign behaviour may demonstrate not only different travel behavior, but may rate their satisfaction with a walking trip differently than those who walk out of necessity. A person who chooses to walk out of a conscious effort to limit green-house gas emissions may be much more tolerant and satisfied with a long walk to her desired destination. Likewise, a person who walks in order to fulfill a desire for physical activity or exercise may in fact prefer a route with a large elevation gain, for example. Lastly, residential self-selection is also a prickly issue that undermines the causal link that many researchers have posited between the built environment and individuals' travel choices. As a decision of where to live relative to a place of work or study establishes the distance, travel time, slope of path and other trip characteristics, it is important to try to understand the complex factors that determine residential choice or to control for them when trying to understand trip satisfaction.

To explore the question of how personal motivations affect perception of travel, an analysis was performed of individuals' satisfaction of walking trips to a downtown university campus. Data collected in winter 2011 documented motivation for using the chosen mode as well as overall satisfaction with the commute. Additional analysis in GIS allowed for the calculation of distance, slope and other trip and neighborhood-level characteristics. This research draws on the response from 671 walkers and sets out to: 1) examine (self-reported) motivations for choosing to walk; 2) explore how the correlation among trip characteristics such as distance, slope and trip satisfaction varies with motivations (and underlying values) and 3) explore issues of residential selection by examining how the characteristics of walking trips and the satisfaction derived from them are related to decisions associated with housing locations.

This paper is structured as follows. A literature review briefly covers theories of travel behavior and decision-making, residential selection, and traveller satisfaction. Afterwards the 
study context and data are presented followed by the analysis. Finally, a conceptual model is presented that ties these strands into one conceptual model and our conclusions and directions for future research are presented.

\section{BACKGROUND}

This paper is premised on the hypothesis that travel behavior, perception, and satisfaction are each correlated with underlying values and motivations such as attitudes towards health and exercise, environmental concerns, and priorities of convenience. The present research forms part of a growing body of work that seeks to question and expand the view that travel by active modes follows patterns that can be generalized across different populations and in multiple contexts. By drawing on elements from traditional utility-based models of behavior, socioecological frameworks, and theories of satisfaction and home-location, this research adds a new conceptual framework of how these important factors inter-relate. For the sake of brevity, this paper does not attempt to offer an exhaustive survey of these diverse fields, but instead briefly presents major theories, and suggests key sources to the interested reader.

A vast literature explores travel behavior and environmental habits and attitudes from a behavioral psychology perspective; however, until recent years this literature often ignored built environment and accessibility measures. On the other hand, much of the work exploring travel behavior in the urban planning literature has focused on built environment and design characteristics but not social forces, priorities, and personal and cultural factors. In the last decade, however, researchers have begun to draw these strands together; much recent research, for example, has confirmed the connection between attitudes towards the environment, health and exercise and the choice of mode (Klockner \& Friedrichsmeier, 2011). Other research 
(Anable \& Gatersleben, 2005) has made the clear distinction between the instrumental and noninstrumental benefits that individuals derive from travel choices.

It has become increasingly accepted that personal values and motivations often play an important — if not dominant-role in mode choice in relation to traditional concerns of speed, cost, or efficiency. In addition to providing access to destinations, travel has been associated with providing therapeutic benefits and physical exercise, satisfying curiosity, raising one's social status, and providing a sense of adventure (Ory \& Mokhtarian, 2005). The associations identified with different types of travel are multiple and overlapping; failure to account for this in transportation research may lead to over-simplistic transport policies. Much work on travel behaviour-and choices more generally—are modelled in a random utility maximization framework which purposefully places all matters related to personal preferences, motivations, and values in the error term (Bohte, Maat, \& Van Wee, 2009). However, recent work has shown how important these issues of personal taste and values are in making decisions. The effect of personal beliefs, motivations, and cultural values, for example, are now often explicitly brought into research frameworks and modelled in statistical analysis. This is a welcome addition to travel behaviour research. In particular, the Hybrid Choice Model developed by Ben-Akiva and colleagues (Ben-Akiva, et al., 2002; Walker \& Ben-Akiva, 2002) takes into account perceptions and attitudes and uses more flexible error structures to better model the realism of choice models. Less work has examined how the satisfaction with a particular mode may also vary greatly by personal factors. Noteworthy recent work on this subject, however, has shown clear evidence of how elements of trip utility are often secondary to personal elements such as overall well-being, socio-economic, and social life when judging the satisfaction with a particular mode or commute (Abou-Zeid \& Ben-Akiva, 2011). 
These dynamic interactions are at the center of the socio-ecological model, which situates the decision-maker in a series of interrelated and nested contexts. These could include such aspects as cultural and national norms, family obligations and customs, neighborhood standards, religious practices, as well as personal expectations and desires. The approach is inherently dynamic and multivariate: that is, the specific array of factors at play ensures that their effects are differentially experienced (Sallis, et al., 2006). Alfonso (2005) explores these social and physical factors as mediating or moderating elements, rather than as predictive, independent variables. An important strength of socio-ecological frameworks is the ease in which these attitudes, perceptions, cultural forces can be incorporated.

\section{Measuring Satisfaction}

Research in the transport field draws on key concepts from work on consumer satisfaction in the fields of marketing and psychology, notably the distinction between positive or negative effect, or the satisfaction with a discrete transaction with some sort of transportation service, and cumulative satisfaction with transportation services over a longer period of time (Friman \& Gärling, 2001). Studies relating to the former category are by far the most common, likely due to the relative ease of cross-sectional data collection (Ettema, Gärling, Olsson, \& Friman, 2010). However, non-instrumental variables such as cleanliness, privacy, safety, convenience, stress, social interaction and scenery have also been found to contribute to transportation-specific satisfaction (Stradling, Anable, \& Carreno, 2007).

Sharing similar concerns to the present study, Páez and Whalen (2010) found that active commuters were most satisfied with their commutes and in fact, most often desired longer journeys to their destinations. In their study of commuters' liking for travel in the San Francisco 
Bay area, Ory and Mokhtarian (2005) examined commuter's liking for travel stratified between long and short distance trips. For short distance trips, they found that those using active modes were most likely to like or strongly like their short commutes (66\%), followed by private vehicle drivers (58\%), rail transit passengers (31\%) and finally bus passengers (8\%). Personal values, such as environmentalist beliefs were shown to have a positive effect on the liking for active modes and rail use.

\section{Residential Self-Selection}

Self-selection refers to "the tendency of people to choose locations based on their travel abilities, needs, and preferences” (Mokhtarian \& Cao, 2008, p. 205) It is important to note that while this complicates the imputation of causality in many travel behaviour studies, the fact that individuals and household locate in locations that fit their needs is clearly not a problem in and of itself, nor does it negate the influence that the built environment does have on behaviour (Naess, 2009). In order to not over- or under-estimate the impacts of neighbourhood built form, residential selfselection is often examined in mode choice studies. However, here the interest in doing so is to facilitate the analysis of the variance in the satisfaction levels of those currently walking with disparate reasons for choosing their current residence. It is hypothesized that those who value the convenience of their location vis-à-vis their work or study location may respond differently to their walking environment than someone who chooses their home for the amenities of the home

or environment. For more on residential self-selection, the interested reader is directed to Van Wee (2009) and Mokhtarian and Cao (2008) for two thorough explorations of this topic. 


\section{RESEARCH FRAMEWORK}

The underlying framework of this research can be seen in Figure 1. Figure 1a shows how objective as well as subjective and perceived elements of a walking trip lead to a certain level of trip satisfaction. Figure 1b explicitly adds the element of personal values as a moderating effect on trip satisfaction. These values include both observed elements from the survey-responses to the motivations for using the mode and home location choices-as well as unobserved elements such as opinions of other modes and the neighbourhood-level social environment. This research attempts to better understand how this moderating force works in the context of satisfaction with walking trips. 


\section{Figure 1: Research framework}

(A)

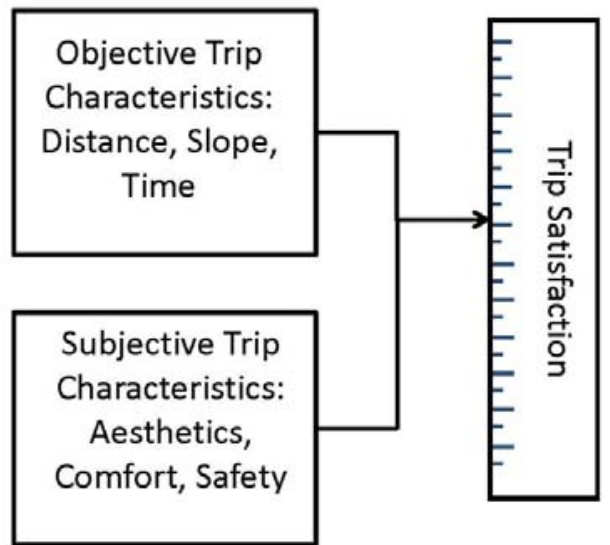

(B)

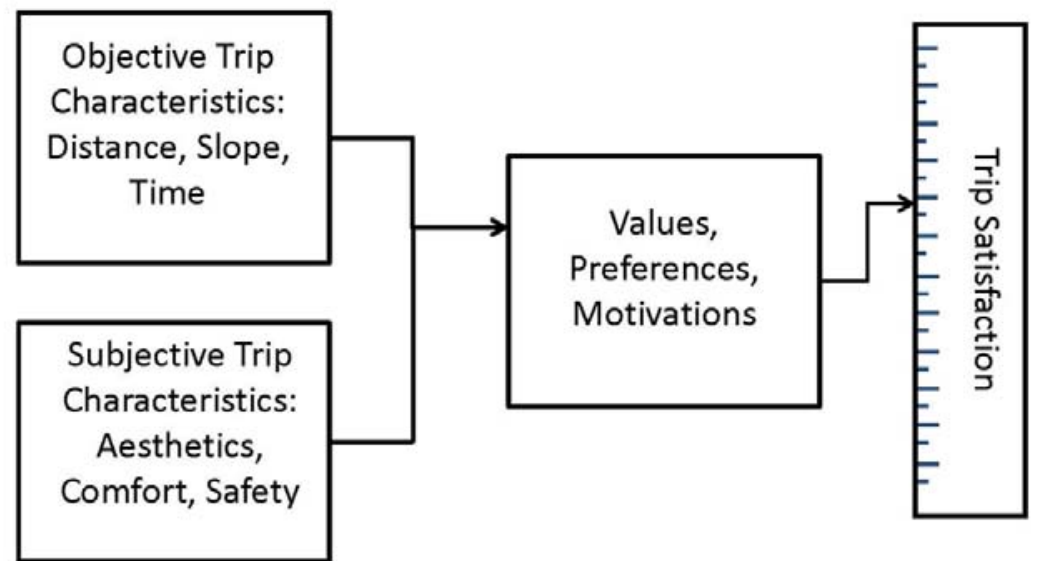

\section{DATA AND STUDY CONTEXT}

The data used in this research is taken from a large-scale travel behavior survey carried out at McGill University in Montreal, Quebec, Canada in consultation with members of the Office of Sustainability of McGill Campus and Space Planning, as well as members of the McGill IT 
Office. With a total population of 36,000 staff, faculty and students, split between a major downtown campus and a much smaller suburban campus, McGill is a major activity generator. The target population of the survey included all McGill students, staff, and faculty. An invitation to participate in the survey was distributed via email, providing recipients with a link to the online survey. While most people associated with McGill have access to a computer and a valid email address, for those staff members that did not have a McGill email address, a postcard inviting them to participate in the survey was mailed to their McGill work location. The survey remained active for a total of 35 days during the month of March and the beginning of April, 2011, during which a total of 19,662 survey invitation emails were distributed among the McGill community. Various prizes were offered as an incentive for survey participation.

As most walkers to the suburban location live on campus and show much less variance in trip characteristics such as distance or slope, only those walkers traveling to the downtown campus were studied, this also permitted us to control for unobserved effects of the walking environment. In addition, by keeping both the trip purpose and location consistent, there are less issues of respondents conflating satisfaction with the trip itself and the destination; which would be an issue if, for example, one were to compare a leisure trip and a work trip to the same location. Satisfaction with walking trips was gauged using a single, Likert-type question where respondents rated their daily commute at one of five levels from 'very unsatisfied' to 'very satisfied'. Table 1 shows the level of satisfaction by status by percentage.

In addition, respondents were asked about their motivations for walking to campus, as well as their reasons for choosing their current home location. This question was structured so the respondent could list the first most important thing that motivated her to walk to campus. Then the respondent was asked about the second most important motivation. The list of 
motivations included an other category for people who had a different response than what was listed in the survey. Similarly two questions on residential choice were included. Table 1 includes the percentages associated with the first and second motivation for walking as well as for selecting the current home location. In order to address possible memory issues as well as changing lifestyle and preferences, the analysed sample was limited to those respondents that moved into their current home location within the last 5 years and whose residential decision followed their beginning of work or study at McGill. In this way, all respondents knew they would be commuting to the McGill campus when the decision to relocate was made.

Responses for those who indicated that they walked to the university in either the winter or the fall were analyzed. Of the roughly 5000 survey responses, 935 were walkers. Of this sample, 671 were selected that fit the above criteria. The final sample included $8.3 \%$ faculty, $5.8 \%$ staff, and $85.8 \%$ students. 
Table 1: Satisfaction by status and responses to motivation and residential choice factors

\begin{tabular}{|l|c|c|c|c|c|}
\hline & Very Unsatisfied & Unsatisfied & Neutral & Satisfied & Very Satisfied \\
\hline Students & $6.4 \%$ & $4.5 \%$ & $21.4 \%$ & $36.8 \%$ & $30.9 \%$ \\
\hline Faculty & $3.6 \%$ & $1.8 \%$ & $16.1 \%$ & $30.4 \%$ & $48.2 \%$ \\
\hline Staff & $15.4 \%$ & $0.0 \%$ & $2.6 \%$ & $30.8 \%$ & $51.3 \%$ \\
\hline Overall & $6.7 \%$ & $4.0 \%$ & $19.8 \%$ & $35.9 \%$ & $33.5 \%$ \\
\hline
\end{tabular}

\begin{tabular}{|l|r|r|}
\hline Motivation for Walking & First & \multicolumn{1}{l|}{ Second } \\
\hline I live close to campus & $54.4 \%$ & $10.1 \%$ \\
\hline It is convenient for me to walk & $18.6 \%$ & $32.6 \%$ \\
\hline Walking is a good form of exercise & $12.5 \%$ & $27.9 \%$ \\
\hline It is a pleasant walk & $5.7 \%$ & $8.8 \%$ \\
\hline Other modes of transportation are too expensive & $5.5 \%$ & $9.8 \%$ \\
\hline Walking is good for the environment & $1.8 \%$ & $6.1 \%$ \\
\hline I do not have access to a car & $1.3 \%$ & $4.2 \%$ \\
\hline Other & $0.1 \%$ & $0.4 \%$ \\
\hline \hline Home Location Reason & First & Second \\
\hline Ability to walk to campus & $48.4 \%$ & $19.1 \%$ \\
\hline Amenities of neighborhood (shops, parks, attractive houses) & $13.0 \%$ & $24.2 \%$ \\
\hline Cost of housing & $8.3 \%$ & $13.1 \%$ \\
\hline Walkability of neighborhood & $7.6 \%$ & $12.9 \%$ \\
\hline This decision was out of my control & $7.5 \%$ & $0.0 \%$ \\
\hline Housing qualities (space, yard etc) & $6.9 \%$ & $9.6 \%$ \\
\hline Being near friends and family & $3.0 \%$ & $9.2 \%$ \\
\hline Proximity to public transit & $1.5 \%$ & $6.2 \%$ \\
\hline Other & $1.3 \%$ & $0.5 \%$ \\
\hline Proximity to areas of interest (work, school, etc) & $1.0 \%$ & $0.7 \%$ \\
\hline Crime and safety & $0.4 \%$ & $2.5 \%$ \\
\hline Ability to cycle to campus & $0.3 \%$ & $1.3 \%$ \\
\hline Quality of schools & $0.1 \%$ & $0.8 \%$ \\
\hline
\end{tabular}


For geocoding purpose, respondents were asked to indicate the postal code attheir place of residence while working/studying at McGill, as well as the area of campus at which they spend the majority of their time while at McGill. The home locations of those who walked to the downtown campus, in addition to the campus itself, are shown in Figure 2. It is important to note that Canadian postal codes are quite fine-grained in scale and correspond to a single block face. Therefore a typical block will have four postal codes, in this way the margin of error is at most approximately +- 100 metres for most of the city.

\section{Figure 2: Study Context}

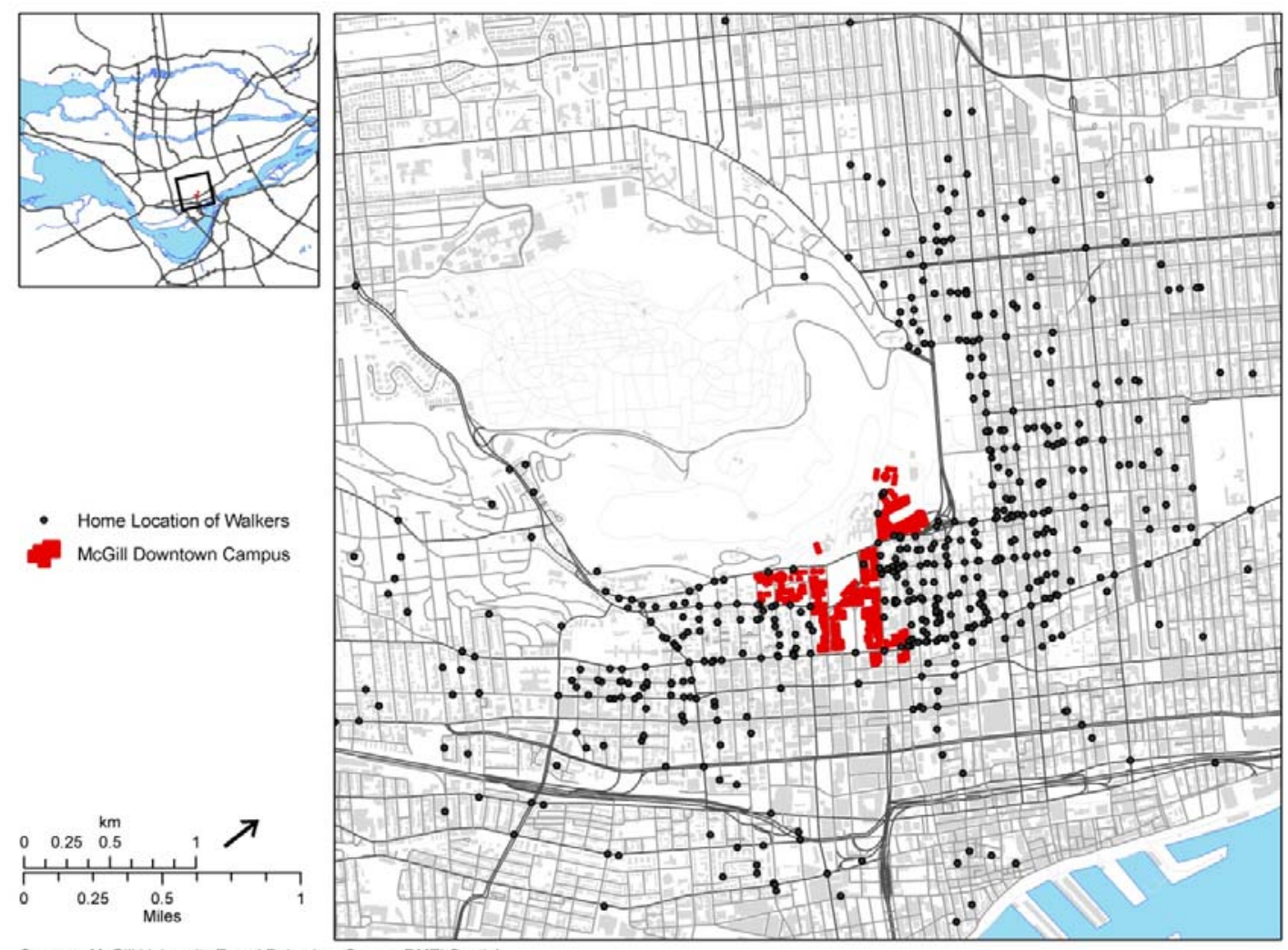

Sources: McGill University Travel Behaviour Survey, DMTI Spatial Projection: NAD 1983 MTM 8 


\section{METHODOLOGY}

As the primary intent of the research was to understand the relationships among trip elements such as slope, travel distance and individual characteristics such as environmental values, several methods were used to gain an insight into these issues. Network analyst in Esri's ArcGIS was used to calculate the shortest route from each residence to the area of campus that the respondent reported as their most common destination. Since McGill is located on the lower slope of Mount Royal (which can be seen in Figure 1 as the large, mostly street-less area north of campus), depending on the location of the origin and the destination, a trip may require a significant elevation gain. Accordingly the line connecting each origin and destination was then tested against changes in topographic contour to determine slope and total elevation change for each trip. As these two elements_-distance and slope-are the most obvious costs or "disutilities" of a walking trip, preliminary analysis of these aspects in relation to trip satisfaction was the first step.

A central supposition of this research is that a person who chooses to walk because they cannot afford transit will have a very different response to elements of their trip than someone who is consciously seeking an active lifestyle or making an effort to limit GHG emissions. In order to explore the motivations of different types of campus users, a two-step clustering process was employed, which grouped the sample of walkers into six distinct categories. The clustering process examined only responses to the questions related to traveller motivations. The possible responses were environmental awareness (“it is environmental friendly to walk”), physical exercise, convenience, affordability, proximity, "because it is pleasant" or because the respondent does not own a vehicle. These responses were designed to elicit variance in traveller values. No other personal characteristics of the respondent were inputted into the clustering 
process. Post-tests evaluated whether the different age, gender, or status make up had an effect on the clustering outcomes.

Distance-decay curves were generated by cluster in order to explore how different groups varied in their walking distances. ANOVA and chi-square analysis are used to confirm and understand statistical significance of the variance between groups. In order to visualize these relationships, a figure plotting satisfaction by distance quintile was constructed. Finally we tested the relationship between the clusters against reasons for selecting home location. This part of the analysis will help in better understanding the self-selection phenomena among walkers.

\section{FINDINGS}

The average distance walked by individuals to campus was 1,247 meters. No clear patterns were found between total walking distance, elevation change and satisfaction levels. For example, there was no significant difference overall between the distance walked between the most and least satisfied individuals (two-sample-test,). Differences in terms of gender, age, and work status were also inconclusive, though staff members were slightly more likely to be both "very unsatisfied" and "very satisfied" than others. These findings suggested the value of looking at motivations and values of travelers to gain a greater insight into how these important aspects may relate to travel outcomes and individual responses. This section highlights important findings, beginning with the results of the clustering.

\section{Cluster Membership}

Two-step clustering is an appropriate approach when dealing with categorical data (Norusis, 2010). The two-step clustering function gave the best fit for 6 clusters-based on Bayesian Information Criterion evaluation. Table 2 presents the clusters by the responses for the 
motivation questions. Please note, these all total $200 \%$ as they are the total of the responses to two motivation questions. The "Close and exercise" cluster therefore each respondent listed proximity and exercise as either their first or second motivation. For the "active environmentalists”, $100 \%$ mention environmental awareness as their first or second motivation while the other response is proximity, cost, exercise, or pleasure. This table reveals that the different groups are quite distinct, with certain motivations for walking shared between groups and others that vary dramatically. Two groups had a significant amount of people citing cost of public transportation or lack of access to a car, these two "barrier" reasons are grouped together in Table 2. The first group is characterised by a high number of people citing reasons of car access and transit affordability, as well as convenience and exercise. The inclusion of the physical activity component is the principal difference between group 1 and 2 . Therefore these two groups have been named "active cost-minimizers" and "close cost minimizers". The next group is characterized by environmental awareness; every respondent in this cluster walks from a self-described desire to engage in environmentally-friendly behaviour, with roughly half also mentioning exercise. In addition many cite the pleasantness of the walks and proximity. This cluster has been named "active environmentalists". The fourth, fifth, and sixth groups present the clearest attributes. Every member of Group 4 mentions both proximity and convenience (as either their first or second reason). Group five mentions both proximity and provision of exercise, while the last group, mentions both exercise and convenience. This is summarized in Table 2 also showing the number of people in each cluster. While not immediately apparent, the important difference between proximity and convenience comes out later in the analysis. 
Table 2: Cluster membership results

\begin{tabular}{|c|c|c|}
\hline Cluster Name & Motivations for Walking & Percent \\
\hline \multirow[t]{4}{*}{ Active cost Mimimizers (134) } & Cost/no car & $58.2 \%$ \\
\hline & Exercise & $54.5 \%$ \\
\hline & Pleasant & $47.0 \%$ \\
\hline & Convenient & $40.3 \%$ \\
\hline \multirow[t]{3}{*}{ Close Cost Mimimizers (88) } & Close & $100.0 \%$ \\
\hline & cost/no car & $68.2 \%$ \\
\hline & Pleasant & $30.7 \%$ \\
\hline \multirow[t]{5}{*}{ Active Environmentalists (53) } & Environmental & $100.0 \%$ \\
\hline & Exercise & $49.1 \%$ \\
\hline & Close & $32.1 \%$ \\
\hline & Pleasant & $13.2 \%$ \\
\hline & cost/no car & $5.7 \%$ \\
\hline \multirow[t]{2}{*}{ Convenience (224) } & Convenient & $100.0 \%$ \\
\hline & Close & $100.0 \%$ \\
\hline \multirow[t]{2}{*}{ Close and exercise (106) } & Close & $100.0 \%$ \\
\hline & Exercise & $100.0 \%$ \\
\hline \multirow[t]{2}{*}{ Convenience and exercise (66) } & Convenient & $100.0 \%$ \\
\hline & exercise & $100.0 \%$ \\
\hline
\end{tabular}

We next examine walking distance and average elevation change of each group in greater detail, with regards to their levels of satisfaction. Taking a closer look at the individuals in the six clusters, we see that not only do their motivations for walking differ dramatically, but so too do their objective travel characteristics such as distance and slope. As the groups are made up of slightly different percentages of age categories; satisfaction levels were checked both with and without various age groups included; this had no significant effect on the results. It is important to reiterate that the clusters were run entirely on responses to questions relating to self-reported motivations and not on any attributes of the trip itself. The fact that distance and satisfaction 
varies so drastically by cluster is in itself an initial confirmation of the usefulness of the technique.

Table 3: Average distance, slope and satisfaction by cluster membership

\begin{tabular}{|l|c|c|c|c|c|c|}
\hline Cluster & Count & $\begin{array}{l}\text { Elevation } \\
\text { change }(\mathrm{m})\end{array}$ & $\begin{array}{l}\text { Very satisfied } \\
(\%)\end{array}$ & Distance (m) & $\begin{array}{l}\text { Min (m) } \\
\text { Distance }\end{array}$ & $\begin{array}{l}\text { Max (m) } \\
\text { Distance }\end{array}$ \\
\hline Active cost Mimimizers & 134 & $61.0^{* *}$ & $19.4 \%^{* * * *}$ & $2034.2^{*}$ & 335.5 & 6068.6 \\
\hline Close Cost Mimimizers & 88 & 29.7 & $25.0 \% * * * *$ & 958.3 & 337.0 & 2354.3 \\
\hline Active Environmentalists & 53 & $57.0^{* *}$ & $52.8 \% * * *$ & $1801.3^{*}$ & 327.0 & 4020.9 \\
\hline Convenience & 224 & 24.6 & $35.7 \%$ & 846.3 & 194.5 & 3267.4 \\
\hline Close and exercise & 106 & 30.9 & $40.6 \% * * *$ & 963.7 & 26.5 & 2862.5 \\
\hline Convenience and exercise & 66 & $51.7^{* *}$ & $39.4 \% * * *$ & $1675.6^{*}$ & 431.6 & 3561.6 \\
\hline
\end{tabular}

$*$ Statistically significant (ANOVA) F(5,671) $=61.18, \mathrm{p}<.01$ (in relation to non-asterisks)

$* *($ ANOVA) $\mathrm{F}(5,671)=37.926, \mathrm{p}<.01$ (in relation to non-asterisks)

$* * *$ Chi-square $(5, \mathrm{~N}=671)=27.58, \mathrm{p}=.0001$, higher than expected value

$* * * *$ Chi-square $(5, \mathrm{~N}=671)=27.58, \mathrm{p}=.0001$, lower than expected value

Chi square and ANOVA were used to understand the variance between the groups. Results are shown in Table 3. ANOVA results found that elevation change and minimum distance were significantly different for two distinct groups. The “close cost minimizers", "convenience", and "close and exercise" clusters differ significantly from the "active cost minimizers", “active environmentalists", and “convenience and exercise” clusters. More interestingly, we see that satisfaction levels are not directly related to distance and slope. The “active environmentalists" have by far the highest satisfaction rates even though they have, on average, some of the longest commutes. The "very satisfied" column shows the percentage of respondents who report being "very satisfied" with their commute. The “active environmentalist," and “close and active”, “active and convenient” groups have a much higher percentage of satisfied individuals than would be expected if satisfaction was randomly distributed throughout each cluster. In addition, the "convenience” cluster, who have the shortest 
average home-to-campus distance show one of the lowest percentages of people who are "very satisfied".

To further explore how satisfaction varies over distance by different groups Figure 3 was constructed plotting the average satisfaction reported by each group against the quintile of distance for each respective group. Quintiles were used for comparative purposes, since the distances walked by each group differed so dramatically. Several findings are presented in Figure 3. First we see that both overall satisfaction rates and their response over distance vary dramatically. For example, a higher percentage of people who walk for environmental or exercise reasons are "very satisfied" with a walk of over 2.8 kilometres than proximity and convenience-seekers walking less than 550 metres. Looking at the response over distance, a clear trend emerges where the values of physical activity and convenience have opposing effects on satisfaction levels. In short, exercise seekers seem to enjoy a longer walk, convenience-seekers do not, and environmentalist have a narrow response to this element of their trips, showing a remarkably high and consistent satisfaction rate across distance quintiles. Plotted this way, we see that the assumed effect of distance only holds true for half of the clusters. For convenience walkers, who walk because of proximity to campus and convenience, their satisfaction clearly declines as distance increases. These findings are useful in understanding potential "thresholds" for satisfaction among different populations; even the most active and environmentally aware people will of course have a limit that they will happily choose to walk. 
Figure 3: Satisfaction by distance quintile

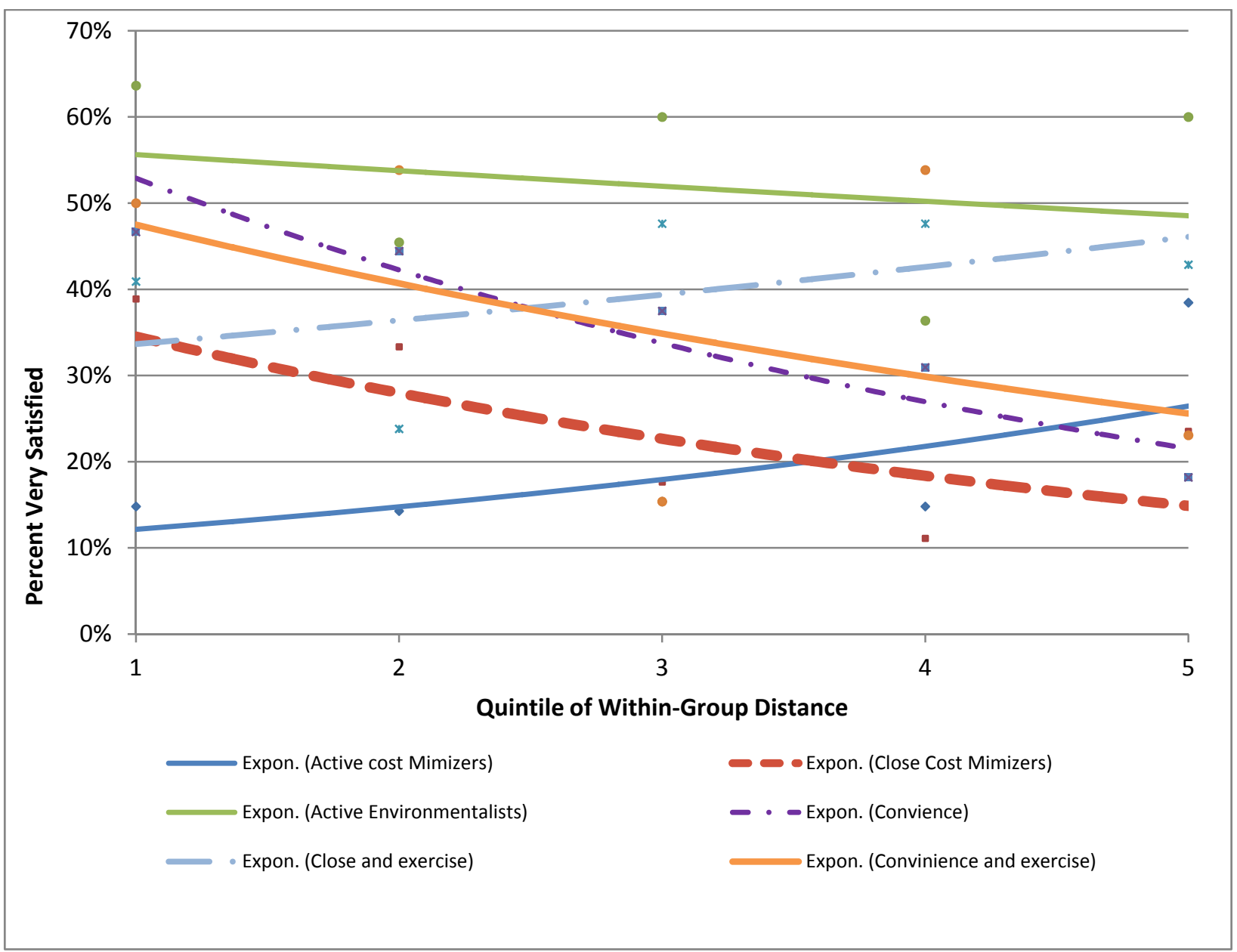

The motivations that individuals have for walking are a strong predictor of the level of satisfaction they are likely to derive from it. As hypothesized, those who walk for environmental or fitness reasons not only tend to walk longer distances but also be more satisfied by their commute. The "convenience-seeking walkers", who value proximity to their destination and overall convenience, display a more expected distance/satisfaction relationship. 


\section{Residential Choice}

While most work on self-selection and travel behavior focuses on mode-choice, the present research takes a different approach. As our sample is made up entirely of people who currently walk and who made their current home location decision with the knowledge that they would be commuting to the McGill campus, the home location decision is seen as the final determinant of trip characteristics such as distance and slope. We are therefore primarily concerned with two questions: What motivated the home location in the first place? and, is there any correlation with expressed satisfaction and walking motivations?

This question was addressed in the present survey by asking respondents for their primary reason for choosing their current home location. Responses by cluster are reported in Table 3, showing the two most common responses by cluster and the percentage of each. The most common response for members of all clusters except "active cost-minimizers" is that it permitted them to easily walk to their destination. "Ability to walk to campus" was the first or second choice for well over $50 \%$ of the respondents in each cluster. However, the "active environmentalists", also cited neighbourhood amenities and proximity of areas of interest more so than most other groups. 
Table 4: Reasons for choosing current place of residence by cluster membership

\begin{tabular}{|c|c|c|c|c|}
\hline & First Response & Percent & Second Response & Percent \\
\hline \multirow{2}{*}{$\begin{array}{l}\text { Active cost } \\
\text { Mimizers }\end{array}$} & Amenities of neighborhood & $28.4 \%$ & Amenities of neighborhood & $39.6 \%$ \\
\hline & Ability to walk to campus & $26.1 \%$ & Proximity to areas of interest & $30.6 \%$ \\
\hline \multirow{2}{*}{$\begin{array}{l}\text { Close Cost } \\
\text { Mimizers }\end{array}$} & Ability to walk to campus & $54.5 \%$ & Proximity to areas of interest & $58.0 \%$ \\
\hline & This decision was out of my control & $13.6 \%$ & Housing quality and cost & $14.8 \%$ \\
\hline \multirow{2}{*}{$\begin{array}{l}\text { Active } \\
\text { Environmentalists }\end{array}$} & Ability to walk to campus & $28.3 \%$ & Amenities of neighborhood & $35.8 \%$ \\
\hline & Amenities of neighborhood & $22.6 \%$ & Proximity to areas of interest & $34.0 \%$ \\
\hline \multirow{2}{*}{ Convenience } & Ability to walk to campus & $61.6 \%$ & Proximity to areas of interest & $66.5 \%$ \\
\hline & This decision was out of my control & $8.5 \%$ & Housing quality and cost & $11.2 \%$ \\
\hline \multirow{2}{*}{$\begin{array}{l}\text { Close and } \\
\text { exercise }\end{array}$} & Ability to walk to campus & $62.3 \%$ & Proximity to areas of interest & $67.9 \%$ \\
\hline & Cost of housing & $7.5 \%$ & Housing quality and cost & $13.2 \%$ \\
\hline \multirow{2}{*}{$\begin{array}{l}\text { Convenience and } \\
\text { exercise }\end{array}$} & Ability to walk to campus & $34.8 \%$ & Proximity to areas of interest & $39.4 \%$ \\
\hline & Amenities of neighborhood & $22.7 \%$ & Amenities of neighborhood & $37.9 \%$ \\
\hline
\end{tabular}

While it was hypothesized that the cross-cluster response to the residential selection questions might shed some light on these issues, overall the response was remarkably consistent for all clusters. Even those in the "convenience" clusters, which appeared to simply be walking out of a lack of better alternatives, do seem to value the chance to engage in active transportation. While initially somewhat surprising, this seems in fact to confirm our hypothesis that these people value the convenience of walking less than the actual experience of walking. 


\section{DISCUSSION}

These findings allowed us to incorporate these elements into one theoretical framework.

Figure 4: Conceptual model

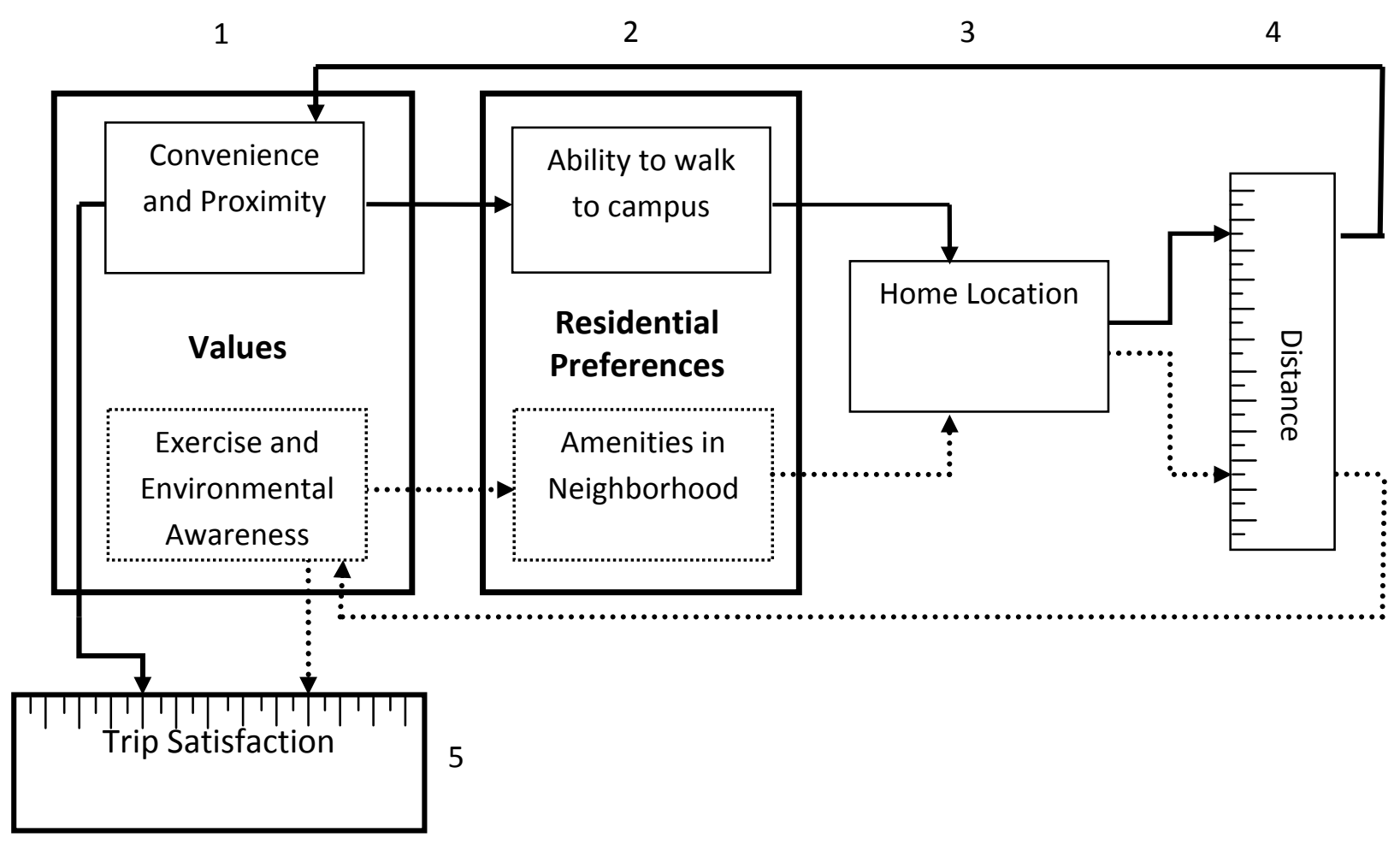

Figure 4 presents the hypothesized path and relationship among underlying values and motivations, home location decisions, walking distance, and satisfaction. We can see that a person who values exercise and environmentally aware behavior may end up choosing a home location that requires a longer walk to her destination than an individual who values proximity and convenience. However, these same underlying values may moderate the effect of distance and slope on trip satisfaction. This framework helps to explain how, in our sample, respondents 
who cited environmental concerns for motivating a walking trip were less likely to make a home location decision based on proximity. Even though these individuals were then walking, on average, a much greater distance than most other respondents, they were, by far, the most satisfied. Furthermore, this framework helps to explain how walkers who value issues of convenience are less satisfied with their walk, even though they walk much shorter than average. The curves shown in Figure 4 are also explained by this framework, while environmentalists show a fairly consistent response to distance, "exercisers" show a positive relationship between distance travelled and satisfaction levels. Those with a self-reported value of "convenience" or proximity are the only groups which show the expected negative correlation with distance. These relationships are further simplified in Figure 5, where the more general conception of "values and preferences" is used. People can have strong or weak, positive or negative attitudes towards environmentally-friendly behavior or physical exercise. These values influence choice of home location and subsequently moderate perception and satisfaction with travel.

\section{Figure 5: Simplified conceptual model}

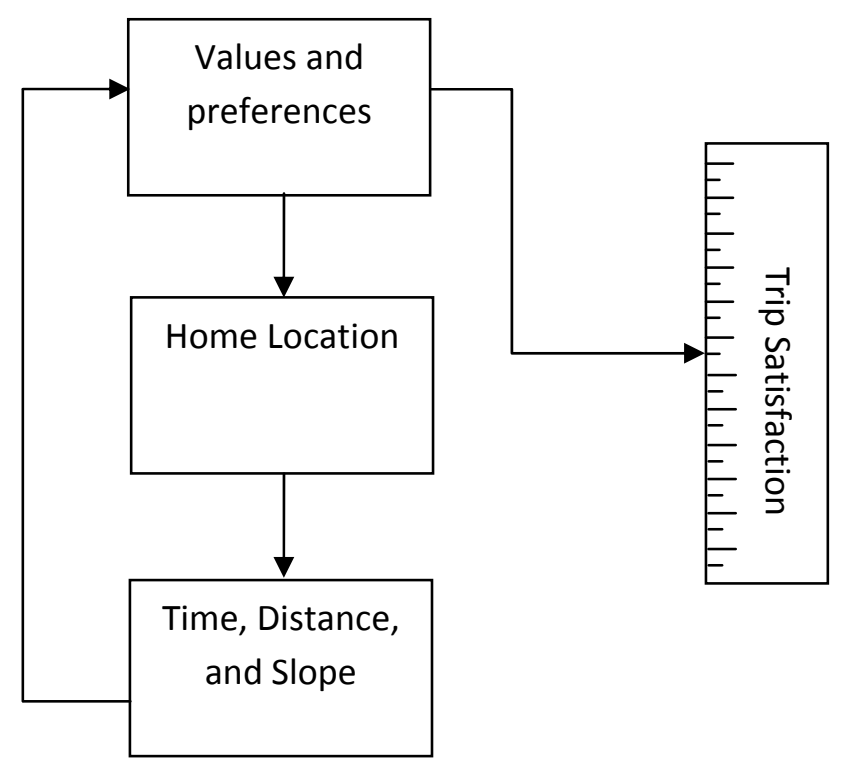


Here we see how underlying values (health, environmental awareness) and preferences for both behavior and housing qualities influencing home location decisions. Once this decision is made, the distance, time, and slope to the desired location is finalized. However, a person's response to these aspects of the trip is then moderated by the same underlying values.

\section{CONCLUSION}

This study aimed to understand the relationship among satisfaction levels, motivations, and home location factors of walkers. This concluding section will highlight the key findings and contributions of this research as well as detail future research directions. This study contributes to walking behavior research in three ways. It presents:

- a deeper understanding of the varied reasons people choose to walk;

- a new understanding of how these motivations are correlated with trip satisfaction; and

- a theoretical framework positing how the same underlying values and motivations lead to home location decision while simultaneously moderating the effect of trip characteristics such as slope and distance.

A considerable amount of past research has been dedicated to understanding how far people will travel to certain types of destinations; however, there has been less study of the satisfaction derived from travel, as well as what motivates different types of travel. This is especially true for those who travel by active modes, which past research suggests do not conform to the common assumptions of utility maximization (Ory \& Mokhtarian, 2005; Paez \& Whalen, 2010). This study aimed to understand the satisfaction levels and motivations of walkers traveling between 
their homes and a shared destination: McGill University's downtown campus. The hypothesis that satisfaction with travel is simply a function of distance walked was eliminated, prompting the categorization of walkers into clusters based on motivation. Incorporating travelers' motivations resulted in the identification of six clusters with dramatically different walking patterns and satisfaction levels. The group of walkers motivated by a desire for exercise, environmental awareness and an appreciation of the aesthetic elements of their journey walk over $1 \mathrm{~km}$ farther than the average. These groups are characterized by a higher overall level of satisfaction than other clusters; furthermore, for this group, satisfaction is either positively associated with distance or has a negligible effect. This is in contrast with the groups citing convenience and proximity, which show a clear inverse relationship between distance and satisfaction. A key importance of this research is simply in distinguishing between the distance that one is "willing" to walk, and the distance that one is "happy" to walk.

Several counterintuitive results were found. A subgroup of commuters who had some of the longest walking commutes (ANOVA $\mathrm{p}<0.01$ )) were also more satisfied (Chi Square $\mathrm{p}<0.001$ ) then would be expected. The distinguishing factor of this subgroup is environmental awareness and the desire to engage in physical exercise. On the other hand, people who value convenience and proximity were less likely to be satisfied with a commute regardless that their commutes were among the shortest. By incorporating the idea of underlying values as both a direct driver of home location decisions and an indirect moderator of how these location characteristics influence an individual's trip satisfaction, a new framework is proposed that helps to explain these surprising results. We argue that by paying greater attention to these aspects among those making active transportation trips, researchers can develop a more nuanced 
understanding of the different types of individuals who adopt these practices, and their diverse reasons for doing so.

The direct policy implications of these results are not obvious. The finding that some people enjoy longer walks certainly does not imply that distances between homes and destinations should be increased. Rather, these findings tend to support rethinking the assumption of the universality of utility-based models of decision-making, a central assumption in the planning and research of transportation networks. A wider set of evaluative measures could be developed and utilized to assess the success of transport policies. While transportation planning goals often focus on modal split and reduction of GHG emissions, this paper argues for the importance of measuring traveler-and in particular, pedestrian—satisfaction. This paper calls on planners and researchers to adopt a broader set of evaluative measures in order to understand the various aspects that contribute to peoples' satisfaction with travel, and the diverse motivations behind it. Much research, and indeed policy direction, seems to be geared toward increasing the modal share of active modes. This research confirms the suspicion that not all people will rate or experience a similar trip in a similar manner. Knowing whether people are walking out of a conscious choice—as opposed to response to their barriers—and are enjoying their travel is arguably a vital aspect. In addition, these findings also point toward the usefulness and value of socio-ecological, mixed logit, and hybrid choice models of walking behavior that take into account personal and social characteristics of neighborhoods, households, and individuals in addition to built environment factors.

One important limitation of this research is that the survey on which it is based included only one question concerning overall satisfaction with travel. Yet, in order to explore the issue of travel satisfaction in sufficient detail, future research should devote greater attention to the 
various aspects of satisfaction, both in terms of specific trips and commuting over time. Issues such as safety, comfort, privacy, sociability, travel time and aesthetic experience would be worthwhile to explore in this regard. It is important to note that questions regarding these aspects are rarely present in most large-scale travel behavior surveys. It is our contention that the inclusion of these types of questions could greatly improve both research and policy outcomes. Future work should test how this relationship persists outside of a sample from in a University setting.

\section{ACKNOWLEDGEMENTS}

We would like to thank the McGill Office of Sustainability and McGill Campus and Space Planning for their feedback and guidance at various stages of this project. Thanks to Jacob Larsen who helped in conducting parts of the literature review for this study. We would also like to thank Daniel Schwartz, from IT Customer Services, for his assistance in developing the online survey and managing the distribution of the survey to the McGill Community. Thanks to Marianne Hatzopoulou, Naveen Eluru, Jacob Mason, Cynthia Jacques, and Vincent Chakour for their help throughout the survey process. We express our gratitude to the McGill Sustainability Projects Fund for partially funding this project. Also thanks to Natural Sciences and Engineering Research Council of Canada (NSERC) for also partially funding this study. 


\section{References}

Abou-Zeid, M., \& Ben-Akiva, M. (2011). The effect of social comparisons on commute well-being. Transportation Research Part A, 45, 345-361.

Alfonzo, M. A. (2005). To walk or not to walk? The hierarchy of walking needs. Environment and Behavior, 37(6), 808-836.

Anable, J., \& Gatersleben, B. (2005). All work and no play? The role of instrumental and affective factors in work and leisure journeys by different travel modes. Transporation Research A, 39, 163-181.

Ben-Akiva, M., McFadden, D., Train, K., Walker, J., Bhat, C., Bierlaire, M., et al. (2002). Hybrid choice models: Progress and challenges. Marketing Letters, 13(3), 163-175.

Bohte, W., Maat, K., \& Van Wee, B. (2009). Measuring attitudes in research on residential self-selection and travel behaviour: A review of theories and emperical research. Transport Reviews, 29(3), 325-357.

Cao, X., Mokhtarian, P. L., \& Handy, S. L. (2009). Examining the Impacts of Residential Self-Selection on Travel Behaviour: A Focus on Empirical Findings. Transport Reviews, 29(3), 359-395.

Ettema, D., Gärling, T., Olsson, L. E., \& Friman, M. (2010). Out-of-home activities, daily travel, and subjective well-being. Transportation Research Part A, 44, 723-732.

Friman, M., \& Gärling, T. (2001). Frequency of negative critical incidents and satisfaction with public transport services. Journal of Retailing and Consumer Services, 8, 95-104.

Hoffman, A. J. (2005). Climate Change Strategy: The Business Logic Behind Voluntary Greenhouse Gas Reductions. California Management Review, 47(3), 21-46.

Klockner, C., \& Friedrichsmeier, T. (2011). A multi-level approach to travel mode choice - How person characteristics and situation specific aspects determine car use in a student sample. Transporation Research F, 14, 261-277.

Manaugh, K., \& El-Geneidy, A. (2011). Validating walkability indices: How do different households respond to the walkability of their neighbourhood? Transportation Research Part D, 16(4), 309315.

Mokhtarian, P., \& Cao, X. (2008). Examining the impacts of residential self-selection on travel behavior: A focus on methodologies. Transoprtation Research Part B: Methodological, 43(3), 204-228.

Naess, P. (2009). Residential self-selection and appropriate control variables in land use: Travel studies. Transport Reviews, 29(3), 293-324.

Norusis, M. (2010). PASW Statistics 18 Guide to Data Analysis: Pearson SPSS Inc.

Ory, D. T., \& Mokhtarian, P. T. (2005). When is getting there half the fun? Modeling the liking for travel. Transportation Research Part A, 39, 97-123.

Paez, A., \& Whalen, K. (2010). Enjoyment of commute: A comparison of different transportation modes. Transportation Research Part A, 44, 537-549.

Sallis, J. F., Cervero, R. B., Ascher, W., Henderson, K. A., Kraft, M. K., \& Kerr, J. (2006). An ecological approach to creating active living communities. Annual Review of Public Health, 27, 297-322.

Stradling, S. G., Anable, J., \& Carreno, M. (2007). Performance, importance and user disgruntlement: a six-step method for measuring satisfaction with with travel modes. Transportation Research Part A, 41(1), 98-106.

Van Wee, B. (2009). Self-selection: A key to a better understanding of location choices, travel behavior and transport externalities. Transport Reviews, 29(3), 279-292.

Walker, J., \& Ben-Akiva, M. (2002). Generalized random utility model. Mathematical Social Sciences, 43(3), 303-343. 
